matous blush has appeared, which disappeared in a fow hours; and in some instances there has been a warked attack of urticaria.

Dr. Morrill, in the Boston Medical and Suryical Journal of January 24, 1895, says that in the Children's Hospital, for the purpose of securing immunity, 50 children were given five cubic centimetres of antitoxin. In no instance was there any injurious result following the injection. Urticaria was noticed in four instances; slight diarrhea in seven ; tomporary increase in micturition in nine; anorexia and slight vomiting in four; well-marked tenderness over the site of the injection in two; erythema around the puncture in three. In onc case 45 cubic centimetres were injected, but the child died sixty hours after the first dose. 'The autopsy proved that the patient died from a broncho-pneumonia and that the death could in no way be attributed to the injection.

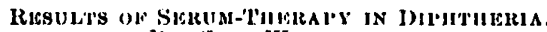
DR. SIMH WOODIIEAD.

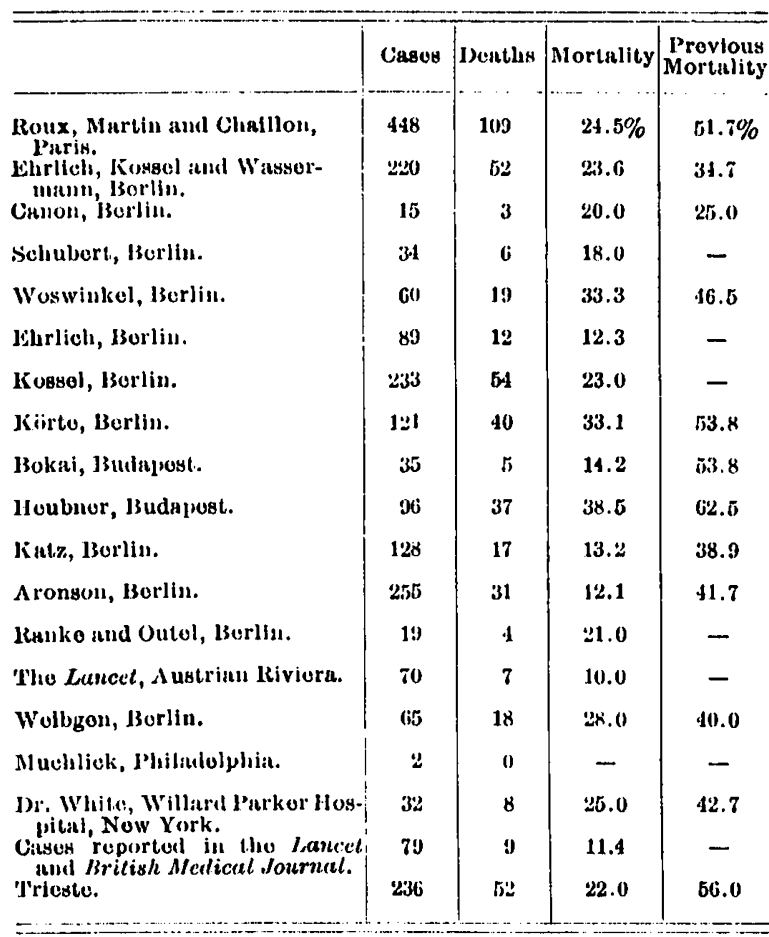

A fow words should be said regarding the manner of using antitoxin. In order to arrive at any satisfactory conclusions, it is all important that in every instance where antitoxin is used, there should be a bacteriological examination of the throat. It is also important that the urine of the patient should bo examined for albumin before and after the injection. 'The dose for procuring immunity, according to some observers, is three cubic centimetres for any ago over three years, and a lialf of that for younger childreu. For a cure of the disease during the first two or three days, under two years of age, ton cubic centimetres; from two to ten yeurs of uge, tifteen cubic centimetres; over ten years of age, twenty cubic centimetres. After the third day, in a sovere case, a larger quantity may be used with positive advantage. If the disease does not seem to be ameliorated by the first lose a second should be given in twelve hours.

Roux states that his practise has been to give twenty cubic centimetres of serum to each pationt on admission to tho hospital, and the same quantity, or half the same quantity, according to the severity of the case, twenty-four hours afterward; and if the pulse and temperature still remain high, the sume dose is repeated. He also adds that the smallest dose that he ever gives, in the first stage of tho discase, is twenty cubic centimetres, and frequently, in severe cases, two or three times as much. There seems to be no doubt from the accounts published abroud as well as from the experience in this city that antitoxin is a remedial agent, of very great efficacy, in the treatment of diphtheria; that it will cure every case has not been claimed, that it is particularly advautageous in cases of mixed infection where streptococci and diphtheria bacilli are associated, has not been proved; but that it is an invaluable agent for the troatment of diphtheria has been abundantly shown.

One advantage of the treatment is, that after tho injection into the back or abdomen there is no interference with the patient; no swabbing of the throat; no tearing of the mucous membrane. It is stated that even in the worst cases that proceed to a fatal end, there is a marked amelioration in the suffering; that the dyspnea is relieved to a certain extent. If the patient dies, his death is comparatively painless.

In regard to the kind of ayringe that should be used, it must bo said that the common subcutancous syringe is not adapted for the purpose, because it cannot bo properly sterilized by heat. Koch's syringe, which consists of a detachable rubber bulb, a glass barrel and a needle, is the most sitisfactory instrument for this purpose. The barrel and steel needle can be put in a test-tube in the bottom of which a little cotton is placed, the tube plugered with cotton, and then put in the oven of a cooking-stove and kept at a temperature of $150^{\circ} \mathrm{C}$., for half an hour or more, or until the cotton is slightly singed. A syringe prepared in this way will remain storilo for four or five days.

In conclusion it may be said, that antitoxin has now been in use for about one year, and that to-day the reports regarding its remedial power aro mado more fuvorable than they were ten months ago. It is, therefore, self-evident that in antitoxin wo have au agent, that, while it will not cure every case of diphtheria, will have a very marked and decided effect in diminishing the death.rate from this discase.

CRITICISM ON TIIS USUAL METHOD OF MEASUREMEN'T OF CHES'T-RXPANSION IN MAFIS-INSURANCL LXAMINATIONS, AND STETHORYRTOGRAPIICAL, STUDIES OF TIIE BILA'TERAL EXPANSION OF THE cHes'l.

BY RlCH. HOQNGH, M.D., WOSTON, MASH.

Mrasurements of thorax circumference on inspiration and expiration have a long time played a certain rôle in determining the condition of the lungs; but they have been put to no more universal use than in life-insurance examinations, where, as a rule, they have been and yet are compulsory.

'The life-insurance companies have their questions to be auswered by the examiver, such as: "Girth of chest under vest, forced expiration? Sume, forced inspiration? Circumference of chest on full expiration In forced inspiration? How many inches does the sub. 
ject measure without coat, round the chest, at the armpits, during forced inspiration and expiration? Is the expansion of the chest normal?" etc. 'Theso questions must be auswered with exact figures or with more or less varying replies, such as, "of normal condition," "of ordinary expansion," or a simple "yes" or "no" - words usually clear enough, but in this case leaving altogether too much scope to individual opinion. In any case the answer must be based upon some kind of measuring, either with an instrument (measuring-tape, spirometer, thorakometer, etc.), or by the eye.

The above quoted questions seem to have gained favor the world over, for they are common to the Old and to the New World's most celebrated life-insurance companies; and yet they are far from being satisfactory, for what physician does not know that the changes in the lungs most to be feared, the tubercu. lous, begin in the apices (therefore high above the nipples, and considerably over the plane of the armpits), also that the total (that is bilateral) capacity may be " normal," while a greater or less part of the lungs is functionally incapacitated? The respective questions, therefore, involve too little, but they could not well be phrased otherwise, in view of the methods at present used.

As to these the thorakometer and compass, also the spirometer and pueumatometer are impractical, while the latter two are in some cases injurious to the health; for which reason the measuring-tape is generally user, which, however, cannot be comfortably and reliably placed any higher than the level of the nipples or thereabouts. Because tho measuring-tupe - which is unsatisfactory - cannot be placed higher than in one plane of the lungs which has so little to do with tuberculosis that it is only attacked in the last stages, the companies have inquired after the condition of the chest at this level, concerning which physicians waste their time in answering. 13y what has already been said, it cun be seen that tape measurements of the "chest's deepest inspiration and expiration" are illusive and should not therefore be employed, especially in such an important examination us that in question. If one may draw conclusions from an unreliable method, the life-insurance company has to take greater risk and the insured porson secures less justice. With life-insurance companies, the rulo which governs shoemakers cannot apply: "that the certain pay for the uncertain"; but as a result of present moasuring methods of the expansion of the chest-it happens not intrequently that some of the insured ones receive "a clear paper," which is not deserved, while others get "a poorer certificate" thun they should justly receive.

I may be permitted to add further criticism on the method of employing measuring-tapes in examination of tho chest expansion.

The method of this measuring with the tape is, as is well known, to place the tape around the "patient's" thorax, from behind, forward, at the height of the nipples; to adjust it as it lies horizontally or somewhat symmetrically on corresponding poiuts, and with the ends or points of contact so placed on the breast, that making fast the zero point, one can at once read its expansion upon the graduated tape. While the examiner tries to hold the tape with an even tension, the person examined breathes in and out as vigorously as he is able, whereupon the band or tape adapts itself as well as it is possible for it to do. The "patient" must, of course, stand as immovable as a statue and in some certain position, but there is no existing rule for this. He is allowed to raise one or both shoulders; bend his head - like a Chinese porcelain imago-back at inspiration, forward at expiration; hold his hauds on his hips, or let his arms hang down loosely; if only he will stand still and sigh the deeper the better - without the examiner appearing to have the least idea what great differences of results occur in different positions. But, furthermore, it sometimes happens that with "weak eyes" and poor light, the examiner, after the deep inspiration lias been made, moves one hand in order to fix the maximum point with the fingers, and then after the deep expiration, moves the other hand to fix the minimum point, in order after the band has been removed, to read between the fingers in some better lighted part of the room the difference between inspiration and expiration. Can uny greater uncertainty in a physical method bo imagined, any greater lack of scientilic exactuess?

He who has undergone observingly, such a measuring of the chest's power of expansion, has not failed to feel the uneven pressure of the measuring band at inspiration and expiration, owing to the fact that the examiner nearly always holds tho band more loosely at inspiration and draws it more tightly at expiration, unconsciously suggesting that it is meant for the company's sake (if done in a life-insurance company's interest) and for the applicants to obtain the greatest possible difference; a phenomenon somewhat like "table moving," when the predisposing thought "it must move" is the power that unconsciously sets both arm and hand muscles and consequently the table in motion.

'The first defect in tape-mensuring is, therefore, that it lacks au unvarying, unbiassed pressure.

The second lies in the fact that the tape band often glides more or less easily, according as the skin is smooth or rough, dry or moist, in which latter case, it sometimes will not move but presses tho skin.

A third defect is that the tape-measurement only records the bilateral total chest-girth. 'Therefore, one cannot measure the right and loft side at the same timo each by itself; and yet this is often necessary, for reasons easily understood. Who has not had experience with the vicarious functions of the organs, or how if one organ is sickly or weakened, its mate works so much tho hurder? For instance, in the case of inflammation of the lungs, tho well lung becomes overworked for the sake of the sick one, etc. 'Therefore, by the use of the measuring-tape, one can easily gain a great bilateral differenco between inspiration and expiration, displaying thus a great sum of capacity even when the expansive power of one lung is lowered, but when the well lung was obliged to bear so wuch greater share of the burden of respiration and to work so much more. 'I'o seek to measure the power of dilatation of the two halves of the chest with the measuring-tupe, first the one from the processus spinosus to the middle of the sternum, and then immediately after the other half, and then to compare the results so obtained, is in the highest degree uncertain (even if the almost impossible case should arise in which every tape-measurement should be accurate); for what guarantee is there that one breath is drawn precisely as deeply as another. It is more probable that 
after a very deop first breath, the lungs are in a sort of apnoe, and the one following is so much the more superficial (because the necessity for respiration this second tine, thanks to O-surplus, is so much less); and the second tape-measurement in this case gives too low a result.

The custom of measuring on a level with the nipples seems passing strange, just as one is surprised that in many blanks, not a word is to be found ubout the height at which the measurement shall be taken, precisely as if it made no difference about tho plane.

When we know that cuberculosis first attacks the apices, and that the more diseased a part of the lung is, just so much more the healthier parts must work, it is easily understood that the coefficient of expansion on the mammillary plane will be, not only relatively too high, but also, perhaps, really greater where there is a mild affection of the apex of the lung than if the person in question were healthy. A great degree of expansion in the mammillary plane may, therefore, be rather a "memento" than a proof of healthy lungs. Why then not take the measures upon the supra- and infra-clavicular regions, or in their immediate vicinity? Simply because it cannot be done with the measuringtape. 'The forward springing posterior and anterior axillary folls are so many hindrances for the measuring-tape, which it cannot gauge so easily as the smooth path round the mammillary plane, and carries the measuring-tape sidewise, upward against the upper chest aperture ; the tape rolls up more or less, or "cuts in" under the arms and is hivdered then in its movements; so that, even if the measuring be not wholly impossible, it will be at least more unreliable.

From this it will appear that the method of measuring the chest-expansion with tape is to be rejected. It does not conform to the exact requirements of science, and therefore should not hold the prominent place it does at present, in so many cases of chest measurement, namely, in life-insurance examinations. 'There is no doubt, on the contrary, that measurements of the thorax expansion may be of great service in making a perfect diagnosis for the fimal decision as to the condition of the lungs, if only a practical and reliable method of examination were adopted. I have, therefore, sought to construct a little autographic instrument which might possess the advantages denied to the measuring-tape, namely, the stethokyrtograph, the description of which is to be found in the New York Medical Record of the 8th of March, 1894, to which you will permit me to refer you.

If it has been dewonstrated that the tape, in measurements of the chest-expansion, as a rule, gives unsatisfactory and unequal results, it cannot, however, be denied that an experienced hand may in favoruble cuses get results approximately good enough to control other weasurements. After a number of tape-meas. urements (for the purpose of getting the right sense in the hands), I have, therefore, made the following conparative measurements between the tape and the stethokyrtograph, in order to test the accuracy of the latter.

COMPARISON BETWEEN THE RESULT OF MEASURlMENT OF CIIEST-KXPANSION WITH THE MEASURING-TAPE ANI) WITH THE STETHOKYRTOGRAP'l.

It can be set down à priori that a critical aud conscientious measuring of the chest with the measuringtape will give a lower result than with the stethokyrto- graph, for, as has been before maintuined, the measuring-tape clings more or less to the body, and so has even on a dry skin a greater resistance to overcome thun the gimp which with the exception of the back, comes only tangentially into contact with the fourteen small metal disce.

On the other hand, the stethokyrtograph would seem to give too high a result, because the gimp slides on the discs three, five, seven or nine millimetres distant from the surface of the bolly. The weight of the cylinders often presses down the discs into the skin and lessens the height; a large part of the gimp nearly touches the skin of the chest ; the " ends of the chain," the two stationery discs, lie lower than the nearest movable discs; the gimp cuts into the back more than glides; all of which conditions, however, clearly reduce the apparently too great result obtained by the use of the stethokyrtograph.

If the results of the measuring-tape, often too low, ${ }^{1}$ be compared with those of the stethokyrtograph, the latter are found to be just as wuch higher as one would suppose the correct ones to be. Also, if the results with the stethokyrtograph should have been too high, this signifies nothing. The most important point is that they give reliable comparisons of the two halves of the chest, between the reapective expansive capacities of the lungs; and this they seem to do.

A computation from Table 7, "Comparison of Bilateral Measurements, etc.," shows that the results with the stethokyrtograph were as follows:

$$
\begin{aligned}
& \text { III } 16.2 \% \text { cnser, } \\
& \begin{array}{l}
16.2 \% \text { enser, } \\
2.7 \% \\
56.7 \% \\
13.5 \% \\
8.1 \% \\
8.1 \% \\
2.7 \%
\end{array} \\
& \text { MA IN:R. } \\
& \text { In } 23.8 \% \text { cases, . }
\end{aligned}
$$

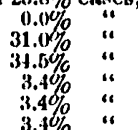

$$
\begin{aligned}
& \text {.5- } 9 \mathrm{~mm} \text {. less than wilh tape. } \\
& \text { the gane as with tupe. } \\
& \text {.5-10 min. groater thill with tapo. } \\
& \text { 14.0 }-20 \mathrm{~mm} \text {. } \\
& \text { 22.0 } 2 \text {-2 ilim. } \\
& 36 \mathrm{~min} \text {. } \\
& \text { FICMA LI:S. }
\end{aligned}
$$

Or collectively, with 66 comparisons of 37 males and 29 females:

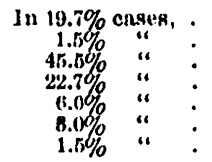

$$
: \vdots
$$

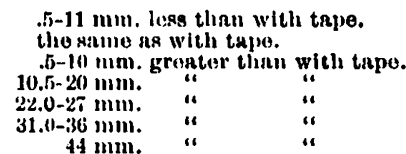

The stethokyrtograph's,superiority has thus been in 45.4 per cent. cuses .5-10 millimetres; or, if one will, in 68.1 per cent. cases one centimetre on the average, depending certainly on its superiority in sliding.

Convinced of the reliability of the stethokyrtograph by thousands of measurements with it, I will now quote only the results of these measuraments in

\section{THE BILATERAL (TOTAL) CHEST-EXPANSION.}

The results have been arranged in tables, ${ }^{2}$ in order to facilitate reference to them, Nos. 1 and 2 contain. ing 517 persons cach (of whom 315 are men, 202 women). Nos. 3 to 6 each contain 636 persons (401 men, 235 women) of varying ages, from three years to nearly ninety years; of unequal height, from that of the dwarf to that of a giant almost; also of different. 1 'This is only a question of the critical and self-evident examinations.

2 For Inok of space, tho tables, with ono exception, linve been
omitted. 
occupations, though the inajority of them belonged to the country population. As lung-tuberculosis has been uppermost in mind, the persons have been placed in four principal groups, according to the condition of the lungs, namely: "Sound," "S.Sound, with prolonged sound of expiration," "Infiltration" and "Consumption." By which is meant that the "Sound" are persous in whose lungs the sound of respiration (in the apices) was softly vesicular and the sound of expiration shorter than that of inspiration; "Sound, with prolonged sound of expiration" are those whose breathing has the same sound as the foregoing group, but in which the expiration sound was at least as long as that of inspiration. Both groups have, as a rule, been "easy-breathing," lauve not lost breath from rumning, climbing stairs, etc. The group "Intiltration" in. cludes cases where the sound of respiration - especially expiration - was rough or harsh, the expiration prolonged, and breathing not so easy as in the foregoing groups. Under "Consumption" have beeu classed those with pueumonia chronica, those with more or less advanced phthisis pulmonis. Other chest diseases, such as chronic bronchitis, heart-fuilure, a couple of cases of pleuritis, etc., have been met, but were so few in numbers that on the whole they signified little. 'They have been grouped according to the above principles.

It is scarcely necessary to add that all who have been examined have had to take the position necessary to the use of the stethokyrtograph, that is, they have stood immovable, with the head bent forward, hands resting lightly on the hips, shoulders still, etc., and the breathing has been "deep and slow," as deep as possible without changing the position of the body in any respect.

On examining Table 1 , we see the 517 persons divided into six groups, according as the expansion of the chest in the "subclavicular plane" was $80 \mathrm{~mm}$. or more, 70 to $79.6 \mathrm{~mm}$., 60 to $69.5 \mathrm{~mm}$., 50 to 59.5 mm., 40 to $49.5 \mathrm{~mm}$., or under $40 \mathrm{~mm}$., independent of the condition of the lungs.

Few persons (18, or 3.5 per cent.) belong to the first group, of greatest expansion, with ages ranging from eight to sixty years, and the height from that of a child to the average of an adult. No height of 180 $\mathrm{cm}$. or above (5 $\mathrm{ft}$. $11 \mathrm{iu}$. or above) has appeared in this group, neither has any consumption. 'The majority of persons having the lungs "Sound, with prolonged sound of expiration" are of average height, 170-179.5 cm. ( $5 \mathrm{ft} .7 \mathrm{in}$. to $5 \mathrm{ft} .11 \mathrm{in}$.), and mostly young or in early middle age, that is, from fifteen to twenty or thirty to thirty-nine years old. Of the eighteen here only one was a woman, of good average height and in her " best years."

The next group, 70 to $79.5 \mathrm{~mm}$., contains 27 persons, or 5.2 per cent., mainly like the foregoing group, with the addition that very tall persons $(180 \mathrm{~cm}$. or more) are found represented here.

'The third group, 60 to $69.5 \mathrm{~mm}$., includes 80 persous, 15.5 per cent. of all examined - persons of all ages, all sizes and of all conditions of the lungs.

The three remuining groups, 50 down to less than $40 \mathrm{~mm}$., with ubout 25 per cent. each of the number oxamined, also include persons of all ages, sizes and couditions of lungs.

The question of the expansion of the chest can be answered, according to Table 1 thus:

'The greatest chest-expansion in the subclavicular plane, $80 \mathrm{~mm}$. or more ( $3 \frac{1}{8} \mathrm{in}$. or more), does not accompany developed consumption, and only in exceptional cases "infiltration."

A chest-expansion on the subclavicular plane of 70 to $79.5 \mathrm{wm}$. ( $2 \frac{y}{4}$ to $3 \frac{1}{8}$ in.) does not accompany developed consumption, but is not infrequent with "infiltratiou."

A chest-expansion on the sane plane, below the last-named limit. can, on the contrary, be met in the perfectly "sound" as well as in those with consump)tion.

Concerning chest-expansion in the mammillary plane, it may be seen by 'Table 2 that on the whole it resembles the subclavicular plane, only being upon an average ubout 10 to $15 \mathrm{~mm}$. higher, according to the anatomical form of the chest, in the majority of cases.

'The numbers in the higher groups have, therefore, increased, while those of the lower groups bave de. creased correspondingly.

In the highest group $80 \mathrm{~mm}$. or more $\left(3 \frac{1}{8} \mathrm{in}\right.$. or more), there is, therefore, no consumption found, but very tall persons ( $180 \mathrm{~cm}$. or over, $5 \mathrm{ft} .11 \mathrm{in}$. or over) have gaiued entrance into this group.' 'The number with "infiltration" has increased.

The next group, 70 to $79.5 \mathrm{~mm}$., contains, on the contrary, several with consumption, and also persons of all ages, sizes and conditions of lungs, precisely like the remaining groups.

The question of the expansion of the chest on the mammillary plave, can, according to 'Iuble 2, therefore be auswered thus:

The greatest chest-expansion on the mammillary plane, $80 \mathrm{~mm}$. or over ( $3 \frac{1}{8}$ in. or over), does not accompany developed consumption, but is not infrequont with "infiltration."

A chest-expansion on the manmiliary plane, below the last-named limit, can, on tho contrary, be met as well with the perfectly "sound," as with those having consumption.

'Table 3 shows only that the plurality of chestexpansions belongs to the smullest sizes; 40 to 69.5 mm., but as a rule, higher numbers for men than for women. A noteworthy exception, however, appears in the group of men tifteen to nineteen years old, "Sound, with prolonged sound of expiration," where, in the sub-clavicular plane, a chest-expansion of 80 ma. or over uppeared in not less than about 25 p.r cent. of cases, and in the mammillary plane on the average, an unusually high expansiou ligured. In the remainiug groups, such a high record of expansion has seldom uppeared.

'Tuble 4 shows how infinitely varying the total chest-expansion can be in the same group of persons, and in the subclavicular as well as in the mammillary plane; it shows us the records of the lowest limit so low that we might think they represcuted only the lightest breathing (and yet the examined ones have done their best to breathe as deeply as possible without changing the position of the body), while the figures of the highest limit are 80 high that they rival the high figures uncritically so often obtained with the measuringtape. 'There is no doubt that some of the lower figures could have been raised, if the patient had practised "breathing after command," for many persons seem to find difficulty in breathing calmly and deeply while the physician stauds ready to measure the expausion of the chest; but in reality these measurements have been made under the same conditions as 
the usual life-insurance examinations, and have, as a rule, been made. without previous training of the patient. Besides, there is a cluss of persons who seem to have a very slight expansion of the chest, even when the condition of the lungs is good; for instance, the very fat, because with them, chest-expansion has been constantly and unexpectedly small, in men as well as women. One often gets the impression from their breathing that they prefer to increase the frequency rather than the depth of their respirations, and that labit finally prevents them from breathing deoply or expanding the chest appreciably which is intensified by a certain change to fat of the outer muscles of respiration in modo circuli vitiosi.

It may be specially stated that the lowest chestexpansion nover accompanied consumption, either in the subclavicular or manmillary plane; and as to the figures recorded in consumption, they are not so low, and many times are as high, ospecially in the mammillary plane, as for "Sound." The greatest chestexpansion that has occurred in the subclavicular plane, $104.5 \mathrm{~mm}$. (4: in.), was that of a professional runner, especially interesting because his lungs gave out a respiratory sound far from normal physiologically. The man had trained his lungs, and what was lacking in quality was supplied by the quantity of vesicular working capacity. The highest figures in the subclavicular plane have belonged to the group" "Sound, with prolonged sound of expirations," and nearly always at all ages (to this belonged the case quoted above), depending, as probably indicated, upon tho fact that while these persons are "sound" in their functions, and the demand on the lungs is in proportion thereto, nature compensates the little change which is here represented by "prolonged sound of expiration" by allowing the chest - that is, the lungs - hyperdilatution, as it were, and for day after day. $\Lambda$ portion of the lung having a pliysiological sound of respiration, the expiration shorter than the inspiration, would, for lack of exercise, not be expanded so excessively, as a rule, as a portion with vosicular respira. tion but with a "prolonger sound of expiration," at least, not before training had come to help it. "This tendency to increase the chest-expansion seoms to continue so long as the part of the lung beneath is not too diseased. For we constantly find it, as before stated, in the subclavicular plane, for the group "Sound, with prolonged sound of expiration," and quite often in the group "Infiltration"; whereas in the group "Cotisumption," although the disposition is certainly to be noticel, it is not sullicient for so great expansion of the chest as in the best cases of tho preceding groups.

Looked at broadly, tho same tendency is detected in the mammillary plane. In the group "Sound" one often gets higher figures that in the subclavicular plane (corresponding, one might think, to the anatomical form of the chest), and therefore in the groups "Sound, with prolonged sound of expiration" aud "Intiltration," often higher figures than in the first named; but what is still more noticeable is, the high figures in the mammillary plano for the group "Consumption" show that the chest-expansion was just as high, sometimes higher, thun for "sound" persons of the sume age.

As to the relution of chest-expausion in the subclavicular and mammillary planes, the latter has generally been 10 to $20 \mathrm{~mm}$. greater in the same person. It has happened often enough, that persons have been found having dilatation in the mannillary plane less than in the subclavicular; and it has often happened that a renewed examination grve the same results, but not infrequently it has depended on the fuct that the patient was tired after the first exumination, which was always the one in the subclavicular plane. The figures in Table 4 do not always correspond, therefore; and probably the tigures in the mammillary plawe would often have been 10 to $20 \mathrm{~mm}$. higher if the examination had begun in that plane. The greatest chest-expansion (106.5 mm., $4 i_{i}^{3}$ in.), was that in the mammillary plane of a "sound" averaged-sized soldier thirty-two years old, with unusually fine chest, and not especially trained lungs.

Moreover, the tables show that during childhood is estublished - because of the more movable chest - a comparatively greater chest-expansion; also that a great expansion of the chest may remain $(80 \mathrm{~mm}$.) even to the early years of middle life.

13y Tables 5 and 6 it appears that the average chest-expansion is not great, and that the difference in the various groups is not so great as ì priori one would expect. If the chest expansion in the subclavicular plane for groups "Intiltration" and "Con. sumption" - which have mostly shown 40 to 49.5 mm. - are excepted, then in the rest of the cuses the expansion in both planes, on an average, has been 50 to $59.5 \mathrm{~mm}$., with distinct tendency, to bo sure, for the consumptives to fall below these figures in the mammillary plaue, even. As we have alreatly seen by 'Iable 4, the expansion of all groups fluctuates considerably, aloove and below these limits. From 'Tables 5 and 6 it is further seen that the chest-expansion of women in all groups has been, as a rule, lower than of men, which has not prevented some exceptions here and there.

Regarding the expunsion of the chest or the bilateral differences between dilatation of the chest with deep inspiration and expiration, as I have already in some regards shown in an article in the New York Medical Kecord, March 3, 1894, p. 264, they seem to vary within considerable limits, in the subclavicular plane from 14 to $104.5 \mathrm{~mm}$. in the groups "sound" and "sound, with prolonged sound of expiration," also from 14 to $81 \mathrm{~mm}$. in the groups "Infiltration", and "Consumption"; and in the mammillary plane from 17 to $106.5 \mathrm{~mm}$. in the former groups, and from 85 to 91.5 in the latter.

The expansion, however, has been in the most of my 517 cases in the subclavicular plane only 50 to $59.5 \mathrm{~mm}$. in the two first groups, and 40 to $49.5 \mathrm{~mm}$. in the secoud two groups; and in the mammillary plane respectively 50 to $69.5 \mathrm{~mm}$. and 40 to $59.5 \mathrm{~mm}$. The measurements were taken only on Swedes.

The result of these studies of bilateral or total chestexpansion is this, that ono cannot, as a rule, draw any conclusions about the condition of the lungs from messurements of the bilateral girth of the chest at the time of deepest inspiration aud expiration, or from measurements of the total chest-expausion in some certain plaue, be they made on the subclavicular or the mammillary plane, and that such measurements, therefore, should not be taken into consideration in life-insurance examinations, and least of all should they be used as the basis of judgment as to the applicaut's place in the "risk scale." The only measurements of the bilateral or total size of the chest which 
ought to exist, and which, therefore, ought to be introduced, are in my' estimation, those as well in the plane of the axillary folds as in the mammillary plane (or at least in the latter), while the chest is at rest, that is to say, during the faintest respiration; because these measurements give a certain idea whether the normal proportions of the body are ascertained or not, precisely as so often happens in the present life-insurance examinations, that the abdomen is measured to see if it corresponds to the proper proportion between abdomen and body's length, etc. For such measurements the tape is adequate, if critically and carefully used; just as surely it is to be condemned in measuring the expunsion of the chest.

If the bilateral (total) measurements of chestexpansion have been cast aside as meaningless, then it remains to investigate whether the "contemporary unibilateral," that is, the "simultaneous single and double-sided" measurements can be of any practical value; but that subject may be left for another paper.

\section{VAGINAL HYS'TERECTOMY AF'LER MAR'TIN'S METHOL. ${ }^{2}$}

BY Howalet) A. ho'muror, A.M., M.D.

Vaginal hysterectomy is now recognized as a perfectly legitimate operation, and is generally acknowledged to be the most desirable mode of procedure in certain cases, hence, most gynecologists are accustomed to practise one or other of the various methods devised for the vaginal extirpation of the uterus. The earliest operation was performed by the elder Langenbeck; but this route for uterine extirpation failed to receive much attention until 1878, when Freund established certain methods of procedure which still serve as the basis for this operation, although different operators have devised more or less rudical modifications.

IIaving had an opportunity to observe the nethods of some of the most skilful operators, the technique alopted by Martin, of Berlin, appears to me as possessing the most advantages, and the reasons for my conclusion I shall hope to make clear later. His early cases date from 1880; but at that time this operation was tedious and attended with considerable risk to life, either from hemorrhage during the operation or from sepsis soon after, while the statistics were far from being encouraging. As performed at the present time by Martin himseli, this mode is the most rapid, attended with the least hemorrhage and fower accidents during the operation, and less liable to be complicated by septic infection during convalescence, thitu any method I have had the opportunity to follow. My sources of information for this communication, are personal observations and Martin's publications.

The indications for uterine extirpation, according to Martin, I will briefly enumerato as follows:

(1) Carcinoma of corpus or cervix.

(2) Sarcoma.

(3) Adenouna.

(4) Certain cases of prolapse not amenable to other less radical mode of treatment.

(5) Also, wherever the patient becomes a chronic sufferer, or runs the risk of losing life by the nonremoval of the uterus, as might occur in : $a$, persistent uterine hemorrhage; $b$, dysmenorrhea persisting in

1 Reud bofore the Obstetrical Seotion of the Sutfolk District Medical Socloty, January $23,1805$. spite of all attempts for relief; $c$, myomata ; $d$, certain suppurative conditions of the uterus; e, certain cases of rupture of uterus in connection with pregnatucy, or as the result of a necrobiotic change.

If feasible, the vaginal route should be chosen; but if not practicable, we should resort to the abdominal method.

'The contraindications for vaginal hysterectomy are :

(1) Extension of malignant disease beyond the uterus.

(2) Large size of that organ, particularly if rigid and not pliable; and these points must be deterwined by the examiner for each individual case.

(3) Presence of adhesions between uterus and other pelvic organs, which render extirpation diflicult and wearisome, and may interfere with convalescence, as being the source of hemorrhage and oozing; and furnishing a nidus for a septic infection.

To this last group belong more than fifty per ceut. of Murtin's fatal cases; and the improverwent in his statistics of late is, in part, due to the fact that he is less prone to operate on these cases per vaginam. Hence, given a case where extirpation is indicated, Martin would choose the vaginal route as most appropriate for some cases, the abdominal for others, and the question of choice would depend on his judgment, there being no hard and fast lines to serve as guides.

PRELARATION FOR OPIERATION.

On the day before operating the patient should take a warm bath, and a suitable cathartic should be administered. Before undertaking such an operation, all patients should be carefully examined while undor the influence of some general anesthetic, in order to determine the exact condition of the pelvic organs, particularly as regards the size of the uterus, the presence of adhesions, and the possibility of any further complications which would contraindicate a vaginal hysterectomy. This opportunity should be taken advantage of, and the vagina carefully cleansed with soap and wator and weak antiseptic solutions. All ulcerations of the cervix should be carefully curetted and cauterized if necessary, so as to remove as wuch source of infection as possible, and then the vagina should be packed with iodoform gauze, which is to be retained until just prior to the operation. If the endometrium is in a septic condition the uterus should be carefully curetted.

Just prior to the operation on the following day, the rectum should be carefully clearsed by enemata, and the anesthetic andministered. At this time the vaginal tampons (if any have been introduced) should be removed, and the vulva and vagina made as aseptic us possible by tho use of weak antiseptic solutions. The bladder is not to be emptied, but is to remain distended with urine until the operation has been completed.

'The only necessary instruments are the following: one perineal and two lateral retractors (after Martin's patteru), two pairs of so-called "bullet forceps," ono pair long curved scissors, one pair long-toothed dissecting-forceps, veedle-holder, several strong curved needles of different sizes, and a scalpel, catgut of large size serves for ligatures and ties. In addition, a douche apparatus should be arranged on the fountuin plan, so that a very small constant stream of boiled water or a solution of corrosive sublimate $(1-20,000)$, cau be made to play over the field of operation, the advan- 